\title{
Non-participation and mortality in a prospective study of cardiovascular disease
}

\author{
MARY WALKER, A G SHAPER, AND D G COOK \\ From the Department of Clinical Epidemiology and General Practice, Royal Free Hospital School of Medicine, \\ London NW3 $2 P F$
}

SUMMARY Men who did not participate in a prospective study of cardiovascular disease (The British Regional Heart Study) were younger than the participants, more likely to be unmarried, and more likely to be less skilled workers. In the first three years of follow-up, their total mortality rate was significantly higher than that of the participants; thereafter it declined to levels not significantly different from those of the participants. This excess of early deaths could not be attributed to age. There was a small but non significant excess mortality in non-participants due to neoplasms and cardiovascular disease and a somewhat greater excess from all other causes combined. The social characteristics of the non-participant population appear to contribute to their significantly higher total mortality rate, and allowance needs to be made for this in interpreting the study findings. However the death rate from cardiovascular disease was similar in participants and non-participants, suggesting that any analysis related to this particular cause of death should not be biased by non-participation.

In all epidemiological studies a proportion of eligible subjects fail to participate. The impact of this nonparticipation on study findings is to compromise the estimation of disease prevalence and incidence, particularly when response rates are low. ${ }^{1}$ There is some evidence that symptomatic disease is overrepresented in participants, ${ }^{2-4}$ whereas asymptomatic disease prevalence is largely unaffected by response bias. $^{56}$ However mortality rates have consistently been found to be higher in non-participants. ${ }^{78} \mathrm{We}$ compare the mortality rates and the demographic characteristics of the non-participants in a prospective study of cardiovascular disease in British middle-aged men with those of the participant group.

\section{Method}

\section{SUBJECTS}

The British Regional Heart Study (BRHS) is a national prospective study of cardiovascular disease in British middle-aged men. The methods of town and practice selection have been published. ${ }^{9}$ The sample consisted of 10412 men aged 40-59 years randomly drawn from four stratified age-bands of the age-sex register of one practice in each of 24 towns. Approximately 420 subjects were selected in each town and they entered the study at a rate of one town per month for a period of two and a half years, from
January 1978 to June 1980 . The doctors were asked to exclude from the initial sample those whom they considered should not be invited because of physical or mental incapacity to participate. Less than 10 men per town were withdrawn for this reason.

\section{CRITERIA}

Participants were those who presented for the clinical examination in response to the invitation from their doctor. Non-participants included those who declined or who failed to reply to the invitation and one reminder, and those who did not receive an invitation because a current address was unobtainable.

\section{FOLLOW-UP}

All 10412 subjects were identified and tagged at the NHS Central Registers in Southport and Edinburgh, and in the event of their death a notification is received by the study centre. The information supplied includes all the usual death registration details, plus the cause of death coded to the 9th Revision of the International Classification of Diseases. Details of the follow-up procedure, which has maintained contact with $99 \%$ of the participant cohort, have been reported. ${ }^{10}$ By 30 June 1986 all men had been in the prospective phase of the study for between six and eight and a half years. The mean length of follow-up was $7 \cdot 2$ years and the results are based on this period. 


\section{SOURCES OF DATA}

1.0 The age-sex registers provided information on the age of all participants and non-participants.

2.0 The death certificates provided demographic and mortality data on the deceased participants and non-participants.

2.1 The informant of death was used as an index for next of kin and was classified into four categories:

(a) wife,

(b) children and their spouses, including step-children,

(c) siblings, including brothers and sisters-in-law,

(d) others, including nephews, nieces, neighbours and others.

2.2 Occupation, as described on the death certificate, was coded into non-manual and manual working categories.

2.3 Cause of death was grouped into three categories: (a) neoplasms, (b) cardiovascular disease, $(c)$ all other causes.

2.4 'Years survived' was computed from screening date to date of death.

3.0 Questionnaire data from the survey provided information on the participants' longest held occupation, and this was coded for social class using the Registrar General's six-category classification.

4.0 Census data. The marital status and social class of the participant group were compared with those of the British male population aged 45 to 64 using 1981 census data, ${ }^{11}$ and with similar data from the appropriate County Reports relating to the 24 towns in the study. From this comparison inferences were drawn relating to the nonparticipants.

\section{Results}

AGE

There was an increase in crude response rate with age from $70.4 \%$ in the youngest age group to $78.2 \%$ in the eldest, with an overall response rate of $74.3 \%$. The mean age of non-participants (49.4 years) was one year lower than that of the participants $(50.4$ years) so that any higher mortality rates found in non-participants could not be attributed to their age.

\section{DEATH RATE}

The overall death rate for the mean follow-up period of 7.2 years was $5.4 \%$ in the 7735 participants $(415$ deaths) and $6.7 \%$ in the 2677 non-participants (179 deaths) (table 1). These figures give a relative risk of death in non-participants of 1.24 with a $95 \%$ confidence interval of $1.08-1 \cdot 45$.

As expected, the death rate by age group for the participants and non-participants rises with increasing age and is higher for non-participants in all four age groups, the difference being most marked in the youngest age group.

ANNUAL DEATH RATE

The annual death rate (table 2 ) is based on consecutive

Table 1 Deaths (number and rate \%) by age group in participants and non-participants for $7 \cdot 2$ years mean follow-up

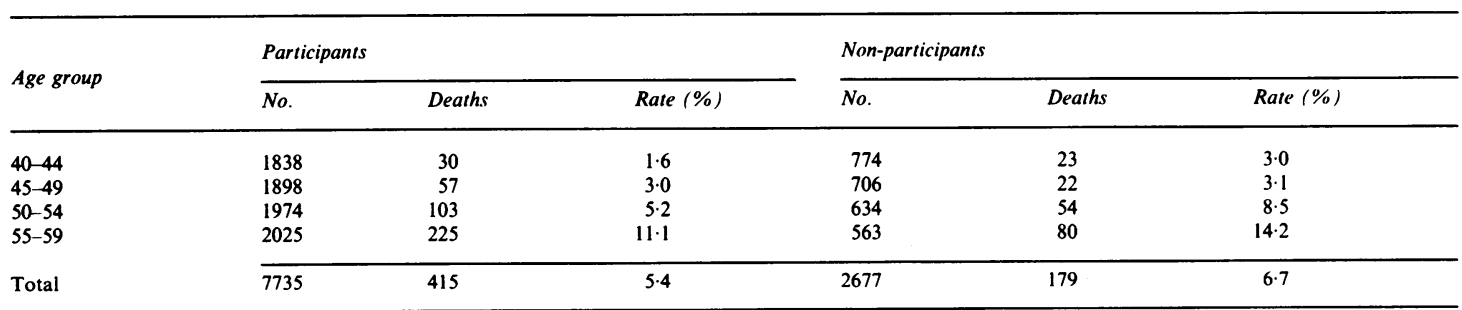

Table 2 Annual death rate (\%) for six years of follow up and relative risk between participants and non-participants

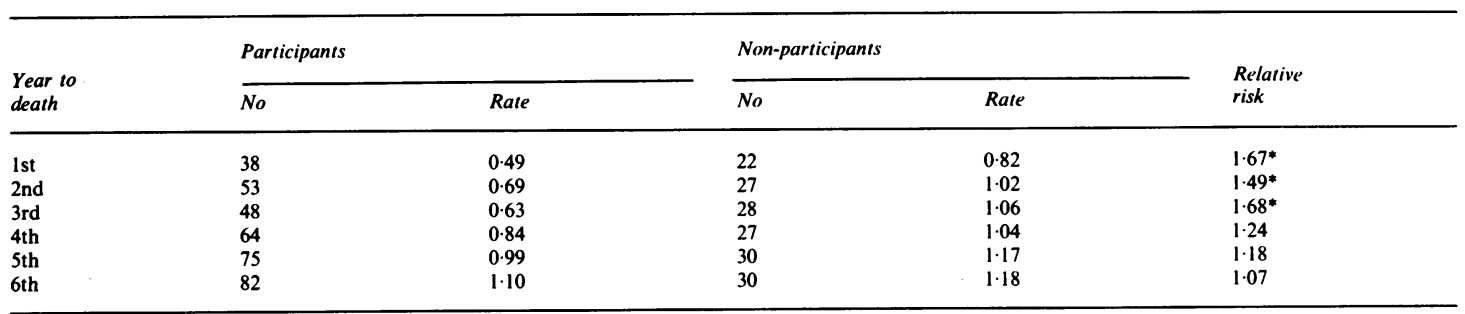

$* p<0.05$

(Fifty five deaths in participants and 15 in non-participants are omitted from this table as they occurred in the 7 th and 8 th years of follow up. 
12-month periods of follow-up for all men. In the first year 38 participants died, giving a rate of $0.49 \%$ per year, and 22 non-participants died, giving a rate of $0.82 \%$ per year. The relative risk of death for nonparticipants in the first year was 1.67 , and this significant excess $(p<0.05)$ was maintained for the first three years from screening. In the fourth and subsequent years the relative risk of death in nonparticipants declined to non-significant levels, associated with a more gradual increase in absolute annual death rates in this group.

\section{CAUSE OF DEATH}

Overall, 594 deaths occurred in the follow-up period. Neoplasms accounted for $31 \%$ of these deaths, cardiovascular disease for $50 \%$ (with four-fifths of these attributed to ischaemic heart disease, ICD $410-414$ ), and $19 \%$ to all other causes. This latter group comprised $5 \%$ due to accident and injury and the remaining $14 \%$ due largely to respiratory diseases and diseases of the digestive system, including the liver.

The death rate for each cause of death was of similar magnitude in participants and non-participants, particularly in the two major categories, neoplasms $(1.7 \%$ and $1.9 \%)$ and cardiovascular disease $(2.8 \%$ and $3 \cdot 1 \%)$. For all other causes the death rate in participants $(0.9 \%)$ and non-participants $(1.6 \%)$ indicates a larger proportionate difference, although the number of deaths in this group is relatively small (table 3). A chi-squared test $\left(\chi^{2}=7.48\right.$ with $\left.2 \mathrm{df} ; \mathrm{p}=0.02\right)$ confirms that the three grouped causes of death are not evenly distributed between participants and nonparticipants, and that the excess of other causes in non-participants is unlikely to have occurred by chance.

\section{MARITAL STATUS}

The informant of a non-participant's death was twice as likely to be someone other than a wife or child compared with the participants $(34 \% \quad v \quad 16 \%$; $\mathrm{p}<0.0001$ ). This suggests that a higher proportion of all non-participants are single men or men without close family support. In BRHS participants, $4.8 \%$ were single men compared with $8.2 \%$ single men in the British population aged 45-64. ${ }^{11}$ This supports the suggestion that single men are under-represented in the participants and over-represented in the nonparticipants.

\section{SOCIAL CLASS}

The social class distribution of men aged 45-64 in Great Britain at the 1981 census is based on their occupation at the time of the census. Compared with the social class distribution of men in the 24 towns in the study (derived from the $10 \%$ sample of heads of households in the County Reports) the six social class categories are remarkably similar and confirm the representativeness of the 24 study towns in terms of social class distribution (table 4).

Table 3 Death rates (\%) and percentage by cause over $7 \cdot 2$ years in participants and non-participants

\begin{tabular}{|c|c|c|c|c|c|c|}
\hline \multirow[b]{2}{*}{$\begin{array}{l}\text { Cause of } \\
\text { death }\end{array}$} & \multicolumn{3}{|c|}{ Participants $(N=7735)$} & \multicolumn{3}{|c|}{ Non-participants $(N=2677)$} \\
\hline & $\begin{array}{l}\text { No. of } \\
\text { deaths }\end{array}$ & $\begin{array}{l}\text { Rate } \\
\%\end{array}$ & $\begin{array}{l}\% \text { of all } \\
\text { deaths }\end{array}$ & $\begin{array}{l}\text { No. of } \\
\text { deaths }\end{array}$ & $\begin{array}{l}\text { Rate } \\
\%\end{array}$ & $\begin{array}{l}\% \text { of all } \\
\text { deaths }\end{array}$ \\
\hline $\begin{array}{l}\text { Neoplasm } \\
\text { CVD } \\
\text { Other }\end{array}$ & $\begin{array}{r}134 \\
216 \\
65\end{array}$ & $\begin{array}{l}1 \cdot 7 \\
2 \cdot 8 \\
0.9\end{array}$ & $\begin{array}{l}32 \\
52 \\
16\end{array}$ & $\begin{array}{l}50 \\
84 \\
45\end{array}$ & $\begin{array}{l}1.9 \\
3.1 \\
1.6\end{array}$ & $\begin{array}{l}28 \\
47 \\
25\end{array}$ \\
\hline Total deaths & 415 & $5 \cdot 4$ & 100 & 179 & 6.7 & 100 \\
\hline
\end{tabular}

CVD $=$ Cardiovascular disease.

Table 4 Social class distribution (\%) in national census (1981), town census data (1981), and in study participants

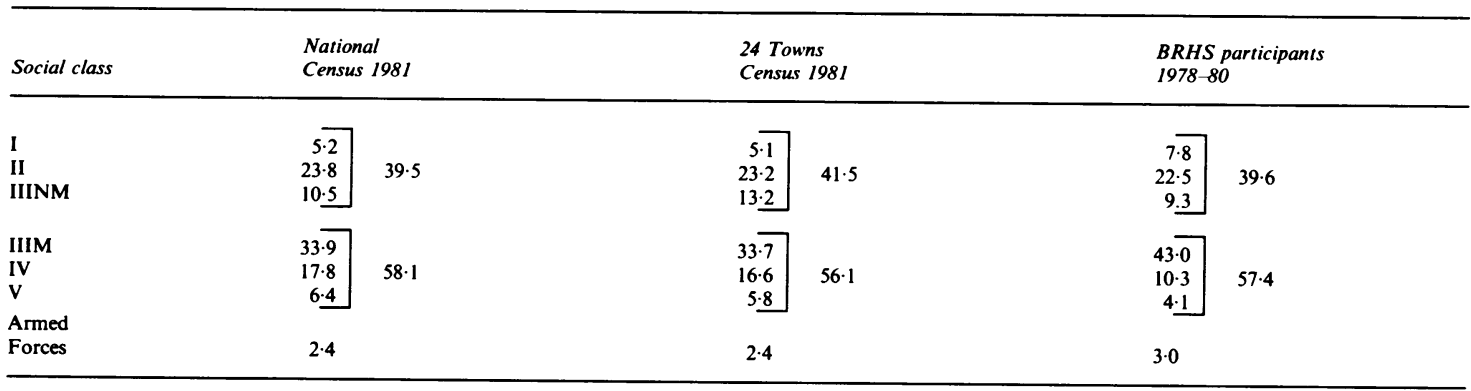


The social class of study participants was based on their longest held occupation, obtained by administered questionnaire. When this distribution is compared with the census data it shows a similarity in the proportion of men who are non-manual or manual workers (approximately 40:60 in both groups), but within these two major categories there appears to be an under-representation in study participants of social classes IIINM, IV, and V with an over-representation of classes I and IIIM.

As the ratio of non-manual to manual workers in the participant group is virtually identical with this ratio in the whole population and in the 24 towns census data, it follows that the non-manual to manual ratio in the non-participants is likely to be of approximately the same order, that is, 40:60. This ratio may therefore be used to calculate the denominators for a manual and non-manual death rate in nonparticipants.

DEATH RATES BY SOCIAL CLASS AND PARTICIPANT STATUS For both participants and non-participants the numerator is the number of deaths recorded and coded to non-manual or manual status according to the occupation on the death certificate. The observed death rate in participants for the mean 7.2 years follow-up period was $5.1 \%$ in non-manual workers and $5.5 \%$ in manual workers (table 5).

For non-participants it is possible, using the nonmanual to manual ratio of $40: 60$, to divide the denominator of all non-participants and estimate the death rates by social class. The estimated death rates are $5.0 \%$ in non-manual workers and $7.4 \%$ in manual workers. These estimated rates give a relative risk of death for manual workers of 1.5 in non-participants, compared with a relative risk of $1 \cdot 1$ in participants.

\section{Discussion}

\section{MORTALITY}

The mortality data in the British Regional Heart Study after an average of 7.2 years of follow-up show that non-participants have a significantly higher relative risk of death during the first three years after the screening date. The higher death rate is not due to the age of the non-participants, nor to any one specific cause of death, although accidents and injury and respiratory and liver disease contribute a larger proportion of deaths in the non-participant group. It is largely the cumulative excess of deaths across all causes which raises the relative risk to significantly higher levels in non-participants. In several other studies, the highest relative risk of death in nonparticipants has been observed in the first year of follow-up. In the present study exclusion of those who were physically and mentally incapable of participating may have prevented this occurring.

\section{CHARACTERISTICS AND RISK FACTORS}

The non-participants in this study contain a higher proportion of unmarried men and a higher proportion of less skilled workers. There is no information on the levels of risk factors in non-participants, but the smoking and drinking habits of participants can be examined by marital status to illustrate the relation of this characteristic to the risk factors. Single and 'other' men have considerably higher smoking rates in terms of both percentage of current smokers and quantity smoked, and their drinking habits are also heavier. This suggests that in the non-participant group, which comprises a higher proportion of single and other men, the prevalence of smoking and drinking habits is likely to be higher and consequently to lead to higher morbidity and mortality rates. Furthermore, among the non-participants there is an excess of social classes IIINM, IV, and V. These social classes have higher rates of drinking and smoking than the other social classes, ${ }^{12}$ adding to the evidence that these risk factors for a number of diseases are likely to be more common in non-participants in this study. Several other studies have investigated these relations and provide supporting evidence.$^{68,13} 14$

Participants tend to have higher morbidity rates for some symptomatic disorders ${ }^{2-4}$ and might thus select themselves into surveys because of their awareness of a problem for which they would welcome further opinion and help. The major risk factors for ischaemic heart disease ${ }^{15}$ are raised blood cholesterol and high blood pressure, both of which are sypmtomless, and cigarette smoking, which is not regarded as a

Table 5 Observed death rate (\%) in participants and estimated death rates (\%) in non-participants for non-manual workers and manaul workers for $7 \cdot 2$ years mean follow-up

\begin{tabular}{|c|c|c|c|c|c|c|}
\hline & \multicolumn{3}{|c|}{ Participants } & \multicolumn{3}{|c|}{ Non-participants } \\
\hline & Observed & Deaths & Rate & Estimated & Deaths & Rate \\
\hline $\begin{array}{l}\text { Non-manual } \\
\text { Manual }\end{array}$ & $\begin{array}{l}3094 \\
4641\end{array}$ & $\begin{array}{l}158 \\
254\end{array}$ & $\begin{array}{l}5 \cdot 1 \\
5 \cdot 5\end{array}$ & $\begin{array}{l}1071 \\
1606\end{array}$ & $\begin{array}{r}54 \\
119\end{array}$ & $\begin{array}{l}5 \cdot 0 \\
7 \cdot 4\end{array}$ \\
\hline
\end{tabular}

*Estimated on a 40:60 ratio. 
'disorder' by those who smoke. In addition, the majority of subjects with evidence of ischaemic heart disease at screening using questionnaire and electrocardiography are unaware of their underlying disorder. ${ }^{16}$ This overall unawareness of risk and disease could explain, at least in part, why participants do not over-represent those at risk from cardiovascular disease. It has been suggested ${ }^{17}$ that men with dependent families have a greater incentive to maintain good health and economic activity and may also receive support and encouragement to participate by their dependents. This would support the evidence of a lower response by the unmarried men.

The differences in the social class distribution within the two broad non-manual and manual categories could contribute to explaining the higher mortality rate found in non-participants since there is a known inverse mortality gradient with social class. ${ }^{18}$ The estimates of the death rates for non-participants by non-manual:manual worker status are based on the only available information and indicate considerably increased risk among the manual working nonparticipants.

In summary, while total mortality rates were found to be higher in non-participants in the first three years from screening, cardiovascular mortality rates were not significantly different from those of the participants. It is unlikely that any analysis related to this specific cause of death, which is the main concern of the British Regional Heart Study, will be biased by factors related to non-participation. However, studies concerned with overall mortality and with specific disorders included in the 'other cause' category should be aware of the bias likely to be produced by non-participation.

The British Regional Heart Study is a British Heart Foundation Research Group and is also supported by the Medical Research Council, DHSS, the Chest Heart and Stroke Association, the Scottish Hospital Endowments Research Trust and the Institute of Alcohol Studies.

\section{References}

${ }^{1}$ Gordon T, Moore FE, Shurtleff D, Dawber TR. Some methodologic problems in the long term study of cardiovascular disease: observations on the Framingham Study. J Chron Dis 1959; 10(3): 186-206.
${ }^{2}$ Cobb S, King S, Chen E. Differences between respondents and non-respondents in a morbidity survey involving clinical examination. J Chron Dis 1957; 6(2): 95-107.

${ }^{3}$ Walker M, Heady JA, Shaper AG. The prevalence of dysuria in women in London. JR Coll Gen Pract 1983; 33: 411-5.

${ }^{4}$ Milne JS, Maule MM, Williamson J. Method of sampling in a study of older people with a comparison of respondents and non-respondents. Br J Prev Soc Med 1971; 25: 37-41.

${ }^{5}$ Silman AJ, Locke CM. Blood pressure distribution in responders and initial non-responders in a population screening study. J Epidemiol Comm Health 1982; 36: 248-50.

${ }^{6}$ Tibblin G. A population study of 50 year old men. An analysis of the non-participation group. Acta Med Scand 1965; 178(4): 453-9.

${ }^{7}$ Wilhelmsen L, Ljunberg S, Wedel H, Werko L. A comparison between participants and non-participants in a primary preventive trial. J Chron Dis 1976; 29: 331-9.

${ }^{8}$ Doll R, Hill AB. Mortality in relation to smoking: ten years' observations of British doctors. Br Med J 1964; i: 1399-1410.

${ }^{9}$ Shaper AG, Pocock SJ, Walker M, Cohen NM, Wale CJ, Thompson AG. The British Regional Heart Study: cardiovascular risk factors in middle-aged men in 24 towns. Br Med J 1981; 283: 179-86.

${ }^{10}$ Walker M, Shaper AG. Follow-up of subjects in prospective studies based in general practice. JR Coll Gen Pract 1984; 3: 365-70.

${ }^{11}$ OPCS Unpublished table. 1981 Census. DT5044U Economically active population: Social class by age, by marital state, by sex.

12 Cummins RO, Shaper AG, Walker M, Wale CJ. Smoking and drinking by middle-aged British men: effects of social class and town of residence. Br Med J 1981; 283: 1497-1502.

13 Bruhn JG. Sociological factors related to participation in a screening clinic for heart disease. Soc Sci Med 1969; 3: 85-93.

${ }^{14}$ Criqui MH, Barrett-Connor E, Austin M. Differences between respondents and non-respondents in a population based cardiovascular disease study. Am J Epidemiol 1978; 108(5): 367-72.

${ }^{15}$ Shaper AG, Pocock SJ, Walker M, Phillips AN, Whitehead TP, McFarlane PW. Risk factors for ischaemic heart disease: the prospective phase of the British Regional Heart Study. J Epidemiol Comm Health 1985; 39: 197-209.

${ }^{16}$ Shaper AG, Cook DG, Walker M, McFarlane PW. Recall of a diagnosis by men with ischaemic heart disease. $\mathrm{Br}$ Heart J 1984; 51: 606-11.

${ }^{17}$ Culyer AJ. Need and the National Health Service. London: Martin Robertson, 1976.

${ }^{18}$ DHSS The Black Report. London: HMSO 1980. 